\title{
Echocardiographic measurement of right ventricular wall thickness in adults by anterior approach
}

\author{
TSUKASA TSUDA, TOSHITAMI SAWAYAMA, NOBUYOSHI KAWAI, * \\ TAKAKAZU KATOH, SHOSO NEZUO, KAZUHIKO KIKAWA \\ From the Division of Cardiology, Department of Medicine, Kawasaki Medical School, Kurashiki, fapan
}

SUMMARY The best way to record the right ventricular wall by echocardiography was investigated in 40 consecutive adult subjects with normal hearts and with various congenital and acquired cardiac disorders.

The right ventricular wall echo was recorded by (1) an anterior approach from the left sternal border in the supine position with 2.25 and $5.0 \mathrm{MHz}$ transducers; (2) a subxiphoid approach with a $2.25 \mathrm{MHz}$ transducer; and (3) an anterior approach in an 80-degree sitting position with 2.25 and 5.0 $\mathrm{MHz}$ transducers.

The highest successful recording rate $(80 \%)$ was obtained by an anterior approach in the supine position with a $5.0 \mathrm{MHz}$ transducer. The recording success rate by an anterior approach in the sitting position was 70 and 37.5 per cent with 5.0 and $2.25 \mathrm{MHz}$ transducers, respectively, and the success rate by a subxiphoid approach was 50 per cent.

The normal range of the right ventricular wall thickness in 25 out of another 32 normal adults examined by the best way was $2.4 \pm 0.5 \mathrm{~mm}$. When divided by body surface area, the normal right ventricular wall thickness index was $1 \cdot 7 \pm 0.2 \mathrm{~mm} / \mathrm{m}^{2}$.

The right ventricular wall thickness of another 21 patients with right ventricular overload ranged from 2.5 to $16 \mathrm{~mm}$, and seemed to correlate well with pulmonary arterial systolic pressure. The right ventricular wall thickness index had a better correlation with pulmonary arterial systolic pressure.

It is concluded that a $5.0 \mathrm{MHz}$ transducer is more suitable for the recording of the right ventricular wall by a standard approach than a $2 \cdot 25 \mathrm{MHz}$ transducer, and this method would be useful for the diagnosis of right ventricular hypertrophy.

Echocardiography seems to have been widely used as a non-invasive method for the examination of the left side of the heart. For the right side there are many problems to be resolved. The method and its usefulness of recording the right ventricular wall by a subxiphoid approach have been previously reported, ${ }^{1}$ but the usefulness of an anterior approach, especially in diagnosing right ventricular hypertrophy in adults, has not yet been established. For this reason the purpose of our present study was: (1) to find out the optimal method for recording the right ventricular wall; (2) to determine the normal range of the right ventricular wall thickness; and (3) to examine the usefulness for the diagnosis of right ventricular hypertrophy.

$\star$ Present address: Division of Cardiology, Seikeikai Hospital, Sakai, Japan.

Received for publication 4 September 1979

\section{Subjects and methods}

\section{OPTIMAL METHOD OF RECORDING RIGHT}

VENTRICULAR WALL

The first object of the study was to find out the best method of recording the right ventricular wall. We studied 40 consecutive patients, 11 of whom were normal subjects, the remaining 29 having various cardiac disorders as shown in Table 1.

At first, each subject was examined echocardiographically in either the supine or left lateral decubitus position as a routine, after which we recorded the right ventricular wall.

The recordings of the right ventricular wall were done in five ways, namely, with $2.25 \mathrm{MHz}$ and again with $5.0 \mathrm{MHz}$ transducers parasternally at the third or fourth intercostal space, first in the supine or 15-degree left lateral decubitus position 
(anterior supine approach) (Fig. 1), and then with a $2.25 \mathrm{MHz}$ transducer through the subxiphoid area (subxiphoid approach) (Fig. 2). Finally, the patients were raised passively to an approximate 80-degree sitting position and the recordings were taken with 2.25 and $5.0 \mathrm{MHz}$ transducers from the left sternal border at the third or fourth intercostal space (anterior sitting approach) (Fig. 3).

For recording the right ventricular wall we chose the beam direction through which the maximal left ventricular transverse dimension could be recorded. When the right ventricular wall could not be recorded distinctly in this direction, the transducer was directed slightly towards the apex until the right ventricular wall endocardium became clear. We concluded each of our studies in one hour even if we were unsuccessful in obtaining a clear right ventricular recording.

The measurement of the right ventricular wall thickness was taken only at end-diastole, that is at the peak of the $\mathbf{R}$ wave on the electrocardiogram. We found that the quality of recording of the right ventricular wall was clear enough to estimate its thickness when the endocardium and epicardium were recorded distinctly at the end of diastole even if the endocardium of the right ventricular wall could not be recorded continuously throughout all of systole and diastole. After the tracings were obtained by our five recording methods, the percentage of those cases whose right ventricular wall thickness could be measured by each method was calculated.
Table 1 Subjects used for study of transducer type and position

\begin{tabular}{llr}
\hline Clinical diagnosis & \multicolumn{3}{c}{40 subjects } \\
\hline Normal & MS & 6 \\
Mitral valve disease & MR & 3
\end{tabular}

ASD, atrial septal defect; old $\mathrm{MI}$, old myocardial infarction; MR, mitral regurgitation; MS, mitral stenosis; VSD, ventricular septal defect.

\section{NORMAL VALUE OF RIGHT VENTRICULAR}

WALL THICKNESS

In the second part of our study another 32 normal subjects, 28 men and four women with a mean age of 50.4 years (range 30 to 75 ), were studied to establish the normal range of right ventricular wall thickness.

These subjects visited our hospital for a check-up, and denied any cardiac symptoms. After the physical examination, chest $x$-ray, exercise electrocardiography (double Master's two-step test), and peripheral blood examinations these subjects were recorded as having no heart disease.

We recorded the right ventricular wall by the method which had the highest recording rate according to our findings, and on an enlarged scale so that we could measure the right ventricular wall
Fig. 1 Tracings obtained by an anterior supine approach with $2 \cdot 25 \mathrm{MHz}$ (left panel) and $5.0 \mathrm{MHz}$ (right panel) transducers. The scale between the right and left panels was different. Left ventricular posterior wall endocardium on the right panel was recorded poorly because ultrasound with higher frequency had greater absorption and scattering. IVS, interventricular septum; $L V$, left ventricle; $L V P W$, le, i ventricular posterior wall; $R V$, right ventricle; $R V A W$, right ventricular anterior wall.
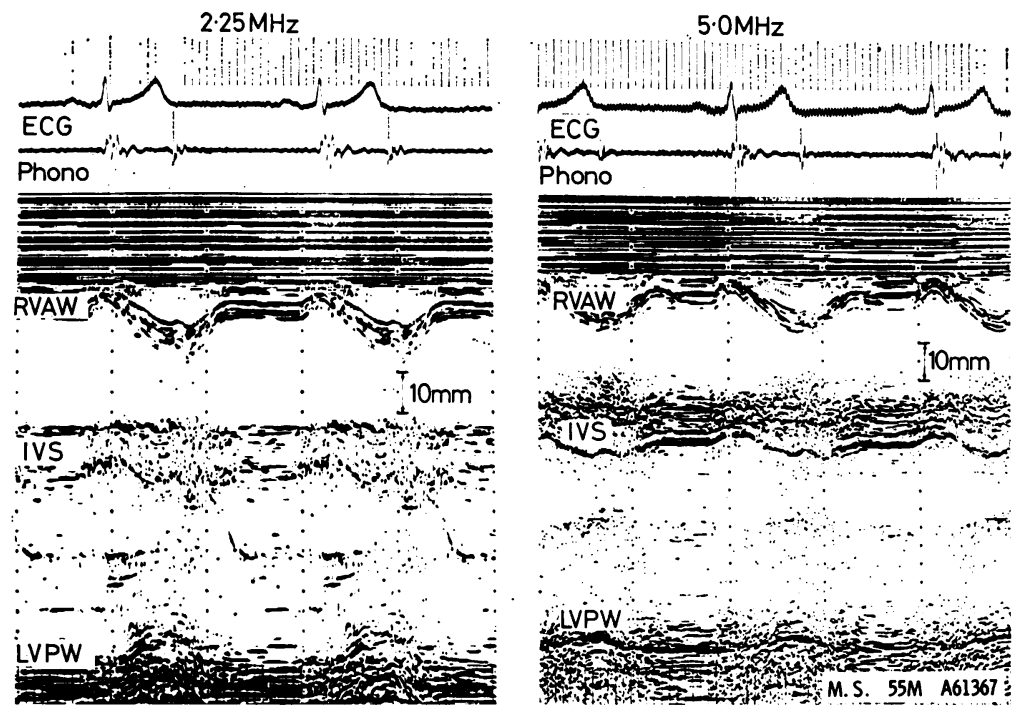
thickness accurately (Fig. 4). The thickness of the right ventricular wall was represented by the distance between the epicardial surface echo and the endocardial surface echo at the peak of the $R$ wave on the electrocardiogram. The right ventricular thickness index was derived from dividing by the body surface area.

\section{CORRELATION OF ECHOCARDIOGRAPHIC AND} HAEMODYNAMIC FINDINGS

In the third part of our study, another 21 patients with various cardiac disorders of right ventricular overload as shown in Table 3, who underwent cardiac catheterisation, were studied to examine the feasibility of diagnosing right ventricular hypertrophy with echocardiography. The echocardiograms of the right ventricular anterior wall were recorded by the same method as the second part of the study. Correlation between the right ventricular anterior wall thickness and pulmonary arterial systolic pressure, and between the right ventricular anterior wall thickness index and pulmonary arterial systolic pressure, were studied.

The echocardiograms were obtained using an Irex echomodule interfaced Irex Continutrace 101 strip chart recorder. A $2.25 \mathrm{MHz}, 12 \mathrm{~mm}$ diameter focused Irex ultrasound transducer and a $5.0 \mathrm{MHz}$, $6 \mathrm{~mm}$ diameter Irex or Aloka ultrasound transducer were used.

\section{Results}

OPTIMAL RECORDING

The tracings were obtained by the five recording

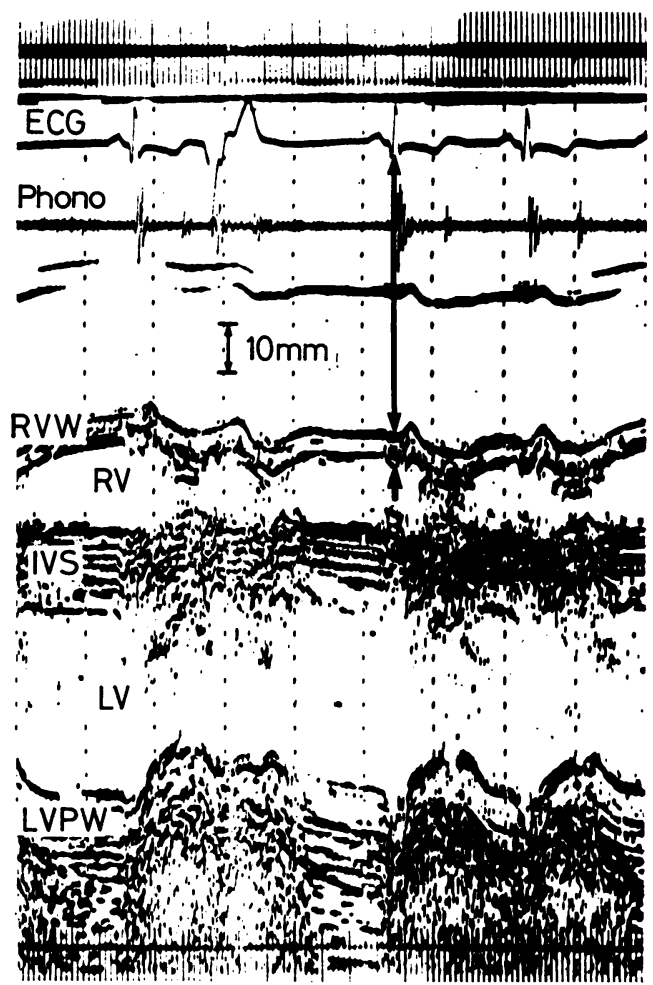

Fig. 2 Tracings obtained by a subxiphoid approach with $2.25 \mathrm{MHz}$ transducer. For abbreviations refer to Fig. 1.

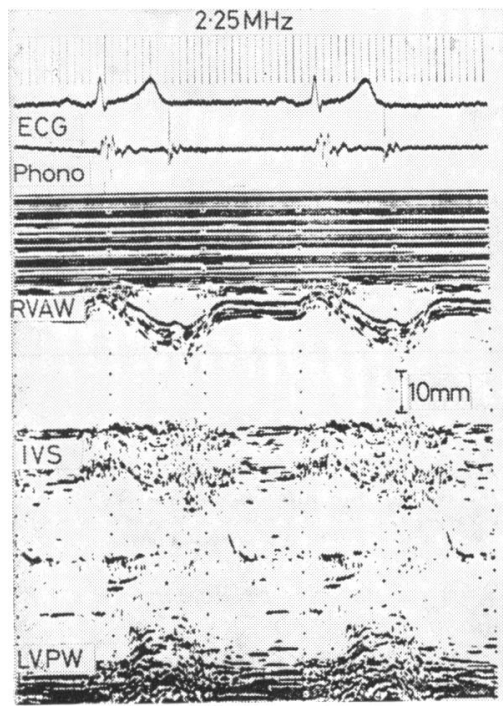

Fig. 3 Tracings obtained by an anterior sitting approach with $2 \cdot 25 \mathrm{MHz}$ (left panel) and $5.0 \mathrm{MHz}$ (right panel) transducers. For abbreviations refer to Fig. 1. 
Fig. 4 Right ventricular anterior wall recordings on an ordinary scale and an enlarged scale using an anterior supine approach with $5.0 \mathrm{MHz}$ transducer. The right panel shows an expanded recording of the right ventricular anterior wall. The right ventricular wall thickness was measured from the upper border of the epicardial echo to the upper border of the endocardial echo. For abbreviations refer to Fig. 1.

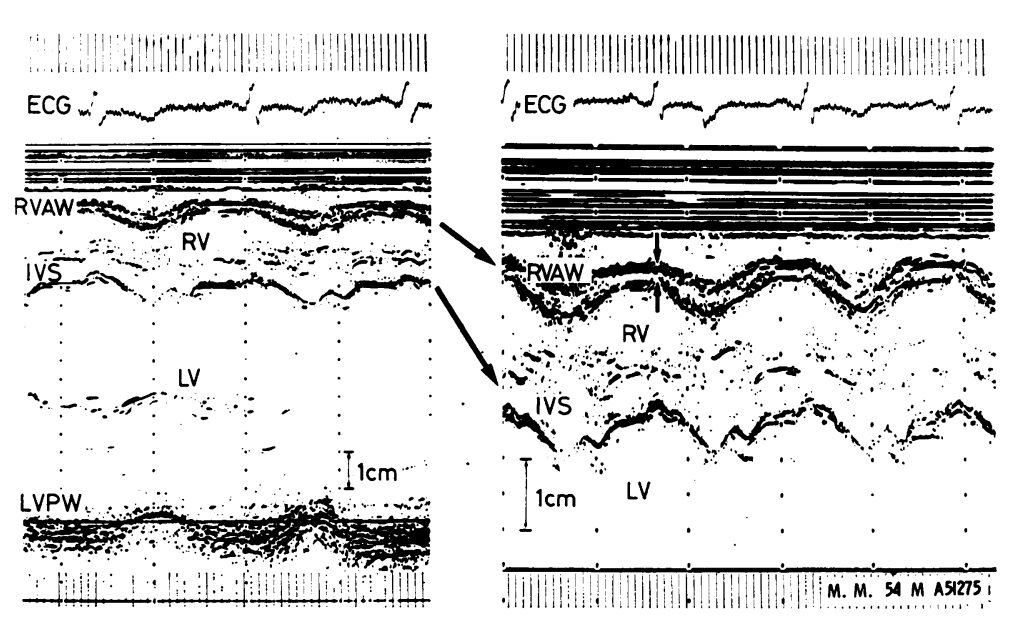

methods, and the percentage of cases whose right ventricular wall could be measured is shown in Table 2. Either in the supine or sitting position the rate of successful recording with the $5.0 \mathrm{MHz}$ transducer was higher than with the $2.25 \mathrm{MHz}$ transducer. The best method for recording was with the patient supine with a $5.0 \mathrm{MHz}$ transducer $(80 \%)$. Using a $2.25 \mathrm{MHz}$ transducer in the supine position, the success rate was 47.5 per cent, and with the 2.25 and $5.0 \mathrm{MHz}$ transducers in the sitting position it was 37.5 and 70 per cent, respectively. A subxiphoid approach with $2 \cdot 25 \mathrm{MHz}$ transducer gave a 50 per cent success rate. When a $5.0 \mathrm{MHz}$ transducer was used in either the supine or sitting position, the success rate was $\mathbf{9 2 . 5}$ per cent.

\section{NORMAL VALUE}

By the best recording method of the right ventricular wall, that is the anterior approach in the supine position with a $5.0 \mathrm{MHz}$ transducer, the righ ventricular walls were clearly recorded in 25 out o 32 normal subjects $(78 \%)$. The normal thickness of the right ventricular anterior wall was $2.4 \pm$ $0.5 \mathrm{~mm}$ (mean $\pm 1 \mathrm{SD}$ ), ranging from 1.8 to $3.5 \mathrm{~mm}$. The right ventricular anterior wall thickness index was $1.7 \pm 0.2 \mathrm{~mm} / \mathrm{m}^{2}$ (mean $\pm 1 \mathrm{SD}$ ).

Table 2 Percentages of successful recordings of right ventricular wall by various methods $(n=40)$

\begin{tabular}{llll}
\hline \multirow{2}{*}{ Transducer } & \multicolumn{2}{l}{ Anterior approach } & $\begin{array}{l}\text { Subxiphoid } \\
\text { approach }\end{array}$ \\
\cline { 2 - 3 } & Supine & Sitting & \\
\hline $2.25 \mathrm{MHz}$ & 19 & 15 & 20 \\
& $(47.5 \%)$ & $(37.5 \%)$ & $(50.0 \%)$ \\
$5.0 \mathrm{MHz}$ & 32 & 28 & \\
& $(80.0 \%)$ & $(70.0 \%)$ & \\
\hline
\end{tabular}

CORRELATION OF ECHOCARDIOGRAPHIC AND HAEMODYNAMIC FINDINGS

The right ventricular anterior wall thickness of the patients with right ventricular overload ranged from 2.5 to $16 \mathrm{~mm}(4.6 \pm 3.1 \mathrm{~mm}$ (mean $\pm 1 \mathrm{SD})$ ). The right ventricular anterior wall thickness index was between 1.6 and $10 \mathrm{~mm} / \mathrm{m}^{2}\left(3.3 \pm 2.1 \mathrm{~mm} / \mathrm{m}^{2}\right)$. Pulmonary arterial systolic pressure ranged from 25 to $120 \mathrm{mmHg}(53 \cdot 8 \pm 32 \cdot 3 \mathrm{mmHg})$.

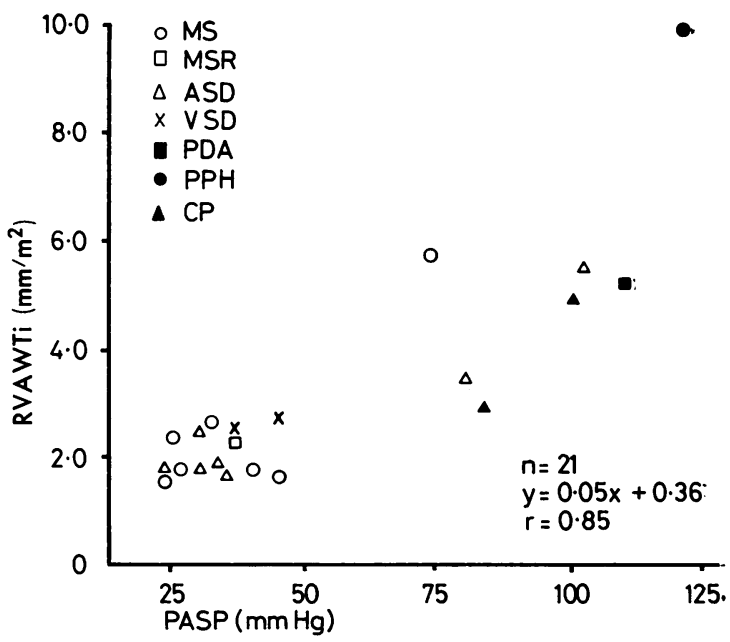

Fig. 5 Relation between right ventricular anterior wall thickness index ( $R V A W T i$ ) and pulmonary arterial systolic pressure (PASP). A good correlation was obtained ( $r=+0 \cdot 85)$. ASD, atrial septal defect; $C P$, cor pulmonale; $M S$, mitral stenosis; $M S R$, mitral stenosis with regurgitation; $P D A$, persistent ductus arteriosus; $P P H$, primary pulmonary hypertension; $V S D$, ventricular septal defect. 
The right ventricular anterior wall thickness had a good correlation with the pulmonary arterial systolic pressure $(r=+0.77)$. The right ventricular anterior wall thickness index gave a better correlation with pulmonary arterial systolic pressure as shown in Fig. $5(r=+0.85)$. An echocardiogram of the patient with primary pulmonary hypertension who had the thickest right ventricular anterior wall $(16 \mathrm{~mm})$ is shown in Fig. 6; his pulmonary arterial systolic pressure was $120 \mathrm{mmHg}$.

\section{Discussion}

There are many reports available concerning the measurement of the left ventricular wall thickness by echocardiography, ${ }^{2-4}$ and its feasibility has been attested to by a good correlation with ventriculography, ${ }^{5}$ and surgical inspection. ${ }^{2}$ Reports related to the thickness of the right ventricular wall, however, have been limited to infants. ${ }^{6-9}$ In adults it is only recently that the subxiphoid approach, ${ }^{1}$ and the standard approach using a $2 \cdot 25 \mathrm{MHz}$ transducer ${ }^{1011}$ have been introduced. But the measurement of right ventricular anterior wall thickness by a standard approach with a $2.25 \mathrm{MHz}$ transducer is usually uncertain because of poor recording. ${ }^{12}$

The impetus to perform this study first came to us when we encountered a patient who could not

Table 3 Echocardiographic and haemodynamic data in 21 patients with right ventricular overload

\begin{tabular}{|c|c|c|c|c|c|c|c|}
\hline $\begin{array}{l}\text { Case } \\
\text { no. }\end{array}$ & $\begin{array}{l}\text { Age } \\
\text { sex }\end{array}$ & and & Diagnosis & $\begin{array}{l}B S A \\
\left(m^{2}\right)\end{array}$ & $\begin{array}{l}R V A W T \\
(\mathrm{~mm})\end{array}$ & $\begin{array}{l}R V A W T i \\
\left(m m / m^{2}\right)\end{array}$ & $\begin{array}{l}P A P \\
(m m H g)\end{array}$ \\
\hline 1 & 41 & $\mathbf{M}$ & ASD & 1.44 & $8 \cdot 0$ & $5 \cdot 6$ & $102 / 50$ \\
\hline 2 & 55 & $\mathbf{F}$ & ASD & $1 \cdot 14$ & $4 \cdot 0$ & 3.5 & $80 / 35$ \\
\hline 3 & 42 & $\mathbf{F}$ & ASD & 1.50 & $4 \cdot 0$ & $2 \cdot 7$ & $32 / 12$ \\
\hline 4 & 45 & $\mathbf{F}$ & ASD & 1.58 & $4 \cdot 5$ & $2 \cdot 8$ & $30 / 15$ \\
\hline 5 & 44 & $\mathbf{M}$ & ASD & $1 \cdot 70$ & 3.0 & $1 \cdot 8$ & $23 / 7$ \\
\hline 6 & 65 & $\mathbf{F}$ & ASD & $1 \cdot 38$ & 3.5 & 2.5 & $30 / 12$ \\
\hline 7 & 22 & $\mathbf{F}$ & ASD & 1.44 & $2 \cdot 5$ & $1 \cdot 7$ & $35 / 10$ \\
\hline 8 & 55 & M & ASD & 1.00 & 3.0 & 1.9 & $33 / 15$ \\
\hline 9 & 56 & $\mathbf{M}$ & VSD & 1.43 & 4.0 & $2 \cdot 8$ & $45 / 14$ \\
\hline 10 & 24 & $\mathbf{M}$ & VSD & 1.55 & $4 \cdot 0$ & $2 \cdot 6$ & $36 / 15$ \\
\hline 11 & 45 & $\mathbf{F}$ & PDA & $1 \cdot 16$ & 6.0 & 52 & $110 / 70$ \\
\hline 12 & 46 & $\mathbf{M}$ & PPH & $1 \cdot 60$ & 16.0 & 10.0 & $120 / 60$ \\
\hline 13 & 49 & $\mathbf{M}$ & CP & 1.40 & $7 \cdot 0$ & $5 \cdot 0$ & $100 / 55$ \\
\hline 14 & 56 & $\mathrm{~F}$ & $\mathrm{CP}$ & $1 \cdot 35$ & $4 \cdot 0$ & 3.0 & $84 / 40$ \\
\hline 15 & 55 & F & MSR & $1 \cdot 39$ & $8 \cdot 0$ & $5 \cdot 8$ & $74 / 30$ \\
\hline 16 & 36 & F & MS & $1 \cdot 26$ & 3.0 & $2 \cdot 4$ & $25 / 14$ \\
\hline 17 & 56 & $\mathrm{~F}$ & MS & $1 \cdot 37$ & 2.5 & 1.8 & $40 / 17$ \\
\hline 18 & 37 & F & MS & $1 \cdot 40$ & $2 \cdot 5$ & $1 \cdot 8$ & $26 / 10$ \\
\hline 19 & 53 & $\mathbf{F}$ & MS & 1.43 & $2 \cdot 5$ & $1 \cdot 7$ & $45 / 25$ \\
\hline 20 & 45 & $\mathrm{~F}$ & MS & 1.52 & 2.5 & $1 \cdot 6$ & $23 / 8$ \\
\hline 21 & 45 & $\mathbf{F}$ & MSR & $1 \cdot 31$ & 3.0 & $2 \cdot 3$ & $36 / 16$ \\
\hline
\end{tabular}

ASD, atrial septal defect; BSA, body surface area; CP, cor pulmonale; MS, mitral stenosis; MSR, mitral stenosis with regurgitation; PAP, pulmonary artery pressure; PDA, persistent ductus arteriosus; $\mathrm{PPH}$, primary pulmonary hypertension; RVAWT, right ventricular anterior wall thickness; RVAWTi, right ventricular anterior wall thickness index; VSD, ventricular septal defect.
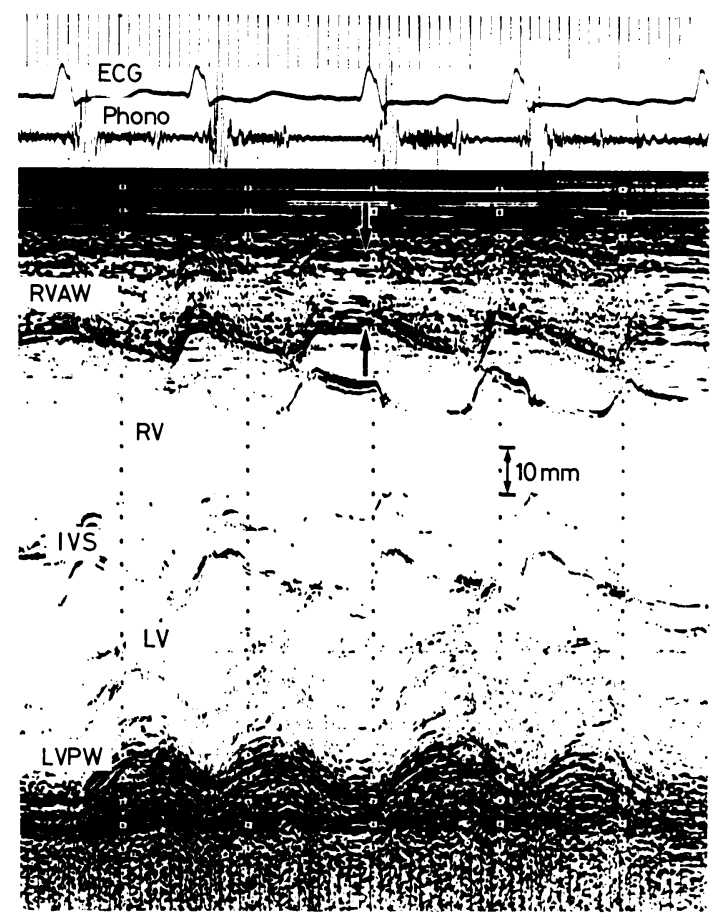

Fig. 6 Echocardiogram by anterior approach with $5.0 \mathrm{MHz}$ transducer in a 46-year-old man with primary pulmonary hypertension (case 12 in Table 3). The right ventricular anterior wall thickness is $16 \mathrm{~mm}$, as indicated by arrows.

assume the supine position because of dyspnoea during an echocardiographic examination. We found that we could make a distinct record of the right ventricular anterior wall endocardium by an anterior approach, with the patient in the sitting position. Then we tried an anterior sitting approach as well as the anterior supine and subxiphoid approach.

\section{BEST METHOD OF RECORDING RIGHT} VENTRICULAR WALL

We found that an anterior supine approach with a $5.0 \mathrm{MHz}$ transducer gave the best results. It is well known that the higher the frequency of a transducer, the greater its resolving power. Our results seem to bear this out. It has been reported that the success rate by a subxiphoid approach was 90.6 per cent $^{1}$ but in our study it was only 50 per cent. Since one of the requirements in the routine examination is to shorten its duration as much as possible, we have limited the time required for one case to 60 minutes. If we had taken longer than our limit of 60 minutes for each method, the percentage of successful recordings might have been slightly 
higher. However, in comparing the results obtained under the same conditions by our five methods, the recording success rate by an anterior supine approach was highest.

NORMAL VALUE

The normal value of the right ventricular wall thickness proved to be $2.4 \pm 0.5 \mathrm{~mm}$, which seems to coincide well with the findings in hearts in Japan brought to necropsy. It has been said that the normal right ventricular wall thickness is from 2 to $3 \mathrm{~mm}$, and right ventricular hypertrophy is diagnosed when right ventricular wall thickness is $3.5 \mathrm{~mm}$ or more in necropsied hearts. ${ }^{13}$ By a subxiphoid approach the right ventricular wall thickness has been reported to have a normal range of $3.4 \pm 0.8 \mathrm{~mm} .^{1}$ Though there are differences between anterior and subxiphoid approaches, our normal values have correlated with those of hearts coming to necropsy ${ }^{13}$ when we used an anterior supine approach. Recording through the subxiphoid may give a slightly greater value because the ultrasonic beam may traverse the right ventricular wall diagonally.

To record the right ventricular wall we chose the beam direction through which the maximal left ventricular transverse dimension could be recorded. When the right ventricular wall could not be recorded distinctly in this direction, the transducer was directed slightly towards the apex until the right ventricular wall endocardium became clear. We believe that this beam direction would also be useful in measuring right ventricular wall thickness more accurately because the beam should traverse the right ventricular wall perpendicularly in order to record it distinctly.

\section{VALIDITY OF ANTERIOR APPROACH WITH}

\section{0 MHZ TRANSDUCER}

The right ventricular anterior wall thickness correlated well with pulmonary arterial systolic pressure. In all 21 patients with right ventricular overload, pulmonary arterial systolic pressure was equal to the peak systolic pressure of the right ventricle because there was no obstruction between the pulmonary artery and the right ventricle. We consider that the right ventricular anterior wall thickness increases in proportion as pulmonary arterial systolic pressure increases whether the right ventricle is volume-overloaded or pressureoverloaded.

The correlation coefficient between the right ventricular anterior wall thickness index and the pulmonary arterial systolic pressure was higher than that between the right ventricular anterior wall thickness and the pulmonary arterial systolic pressure. This indicates that the right ventricular anterior wall thickness index is more suitable for diagnosing right ventricular hypertrophy than the absolute value of the right ventricular anterior wall thickness.

\section{CLINICAL IMPLICATION}

Electrocardiographically, it is often difficult to diagnose right ventricular hypertrophy and biventricular hypertrophy, especially in cases with bundle-branch block or Wolff-Parkinson-White syndrome. Sometimes it is also difficult to differentiate right ventricular hypertrophy from true posterior wall infarction. The present study indicates that echocardiography by standard approach with a $5.0 \mathrm{MHz}$ transducer is useful for diagnosing right ventricular hypertrophy even in these cases because this method provides an adequate visualisation of the right ventricular anterior wall, facilitating the measurement of its thickness.

\section{Conclusion}

(1) The best method of recording the right ventricular wall after testing two transducers and three approaches proved to be an anterior approach in the supine position with a $5.0 \mathrm{MHz}$ transducer.

(2) The normal range of the right ventricular wall thickness measured in 25 normal subjects by the best recording method was $2.4 \pm 0.5 \mathrm{~mm}$. This gave the thickness index of $1 \cdot 7 \pm 0.2$ when divided by body surface area.

(3) Recording the right ventricular wall can be made successfully by a standard approach (anterior approach) when a 5.0 MHz transducer is used, and this method is considered to be valuable in the diagnosis of right ventricular hypertrophy.

We thank Mr Seiichi Yamamoto for his expert technical assistance, and Dr Jules Constant, Buffalo General Hospital, for reviewing this manuscript.

\section{References}

1 Matsukubo H, Matsuura T, Endo N, et al. Echocardiographic measurement of right ventricular wall thickness: a new application of subxiphoid echocardiography. Circulation 1977; 56: 278-84.

2 Feigenbaum H, Popp RL, Chip JN, Haine CL. Left ventricular wall thickness measured by ultrasound. Arch Intern Med 1968; 121 : 391-5.

3 Siögren A-L, Hytönen I, Frick MH. Ultrasonic 
measurement of ventricular wall thickness. Chest $1970 ; 57: 37-40$.

4 Askanas A, Rajszys R, Sadonski Z, Stopczyk M. Measurement of the thickness of the left ventricular wall in man using the ultrasound technique. Pol Med f $1970 ; 9$ : 62-6.

5 Feigenbaum H, Popp RL, Wolfe SB, et al. Ultrasound measurements of the left ventricle. A correlative study with angiography. Arch Intern Med 1972; 129: 461-7.

6 Solinger R, Elbl F, Minhas K. Echocardiography in the normal neonate. Circulation 1973; 47: 108-18.

7 Hagan AD, Deely WJ, Sahn DJ, Fiedman WF. Echocardiographic criteria for normal newborn infants. Circulation 1973; 48: 1221-6.

8 Goldberg SJ, Allen HD, Sahn DJ. Pediatric and adolescent echocardiography. Chicago: Year Book Medical Publishers, 1975: 35.

9 Gewitz M, Eshaghpour E, Holselaw DS, Miller HA, Kawai N. Echocardiography in cystic fibrosis. Am $\mathcal{F}$
Dis Child 1977; 131: 275-80.

10 Prakash $R$, Lindsay $P$. Determination of right ventricular wall thickness by echocardiogram. $\mathscr{F} A M A$ 1978; 239: 638-40.

11 Prakash R. Determination of right ventricular wall thickness in systole and diastole. Echocardiographic and necropsy correlation in 32 patients. Br Heart $\mathcal{F}$ 1978 ; 40: $1257-61$.

12 Sahn DJ, Denaria A, Kisslo J, Weyman A. Recommendations regarding quantitation in $\mathrm{M}$-mode echocardiography: results of a survey of echocardiographic measurements. Circulation 1978; 58: 107283.

13 Mori S. Textbook of special pathology (in Japanese). Tokyo: Kanehara Publication, 1964, 22.

Requests for reprints to Dr Tsukasa Tsuda, Division of Cardiology, Department of Medicine, Kawasaki Medical School, 577 Matsushima, Kurashiki, 701-01 Japan. 